\title{
Direct and indirect costs in the conservative management of undisplaced scaphoid fractures
}

Received: 12 May 2003 / Accepted: 15 July 2003 / Published online: 6 September 2003

(C) Springer-Verlag 2003

\begin{abstract}
The scaphoid is the most commonly fractured carpal bone, and preferable treatment of undisplaced fractures is controversial. In order to assess the socioeconomic impact of treatment modalities, we analysed the cost of conservative management of 54 undisplaced scaphoid fractures. Global costs amounted to 14.077 Swiss francs (9385 euros) per patient. Direct costs represent only $10 \%$ of global costs. No significant correlation was found between costs and timing of diagnosis, hand dominance or complications. Thirty-four percent of patients were able to resume their job with the wrist immobilised without complication, but at an obvious impact on indirect and global costs. If early resumption of professional activities during conservative treatment of undisplaced scaphoid fractures does not impair successful fracture healing, patients should be encouraged to return to work as early as possible, as is routinely done after percutaneous fracture fixation. This will contribute to massively reducing the cost of conservative treatment.
\end{abstract}

C. Fusetti · U. Büchler · L. Nagy

Division of Hand Surgery,

Department of Orthopaedics, Plastic and Hand Surgery,

University of Bern, Inselspital, Bern, Switzerland

C. Fusetti ( $\square)$

Hand Surgery Unit, University Hospital Geneva,

CH-1211 Geneve, Switzerland

E-mail: cfusetti@yahoo.com

Tel.: +41-21-3723311

G. Garavaglia

Orthopaedic Surgery, Department of Surgery,

Hôpitaux Universitaires, Geneva, Switzerland

M. Y. Papaloizos

Centre de Chirurgie et de Thérapie de la Main,

Geneva, Switzerland

J. B. Wasserfallen

Medical Direction, Centre Hospitalier Universitaire Vaudois, Lausanne, Switzerland
Keywords Scaphoid fracture $\cdot$ Immobilisation $\cdot$ Costs

\section{Coût du traitement conservateur des fractures} du scaphoïde

Résumé Le scapho est l'os du carpe le plus souvent fracturé et le traitement idéal de la fracture non déplacée reste source de controverses. Nous analysons les coûts et l'impact socio-économique du traitement conservateur de 54 fractures non déplacées du scapho carpien. Le coût total s'élève à 14'077 francs suisses par patient $(9385$ euros) dont $10 \%$ seulement représenté par les coûts directs. Aucune relation statistique n'est retrouvée entre les coûts et le délai diagnostique, la dominance ou la survenue de complications. $34 \%$ des patients ont pu reprendre une activité professionnelle pendant la période d'immobilisation sans complications mais avec un impact évident sur les coûts indirects et globaux. Dans notre série la reprise précoce de l'activité professionnelle n'interfère pas avec la consolidation osseuse et nous encourageons nos patients à reprendre leur travail précocement, comme préconisé après une fixation percutanée. Notre attitude permet une réduction significative des coûts du traitement conservateur.

Mots clés Fracture du scaphoide

Immobilisation · Coûts

\section{Introduction}

The scaphoid is the most commonly fractured carpal bone, and these fractures most often occur in young and active patients. So far conservative treatment has been the gold standard for undisplaced fractures and consisted in cast immobilisation for 8-12 weeks.

With the advent of percutaneous techniques, applying dedicated implants, scaphoid fractures can be stabilised and rapidly loaded so that serious doubts and worthwhile dispute about the preferable treatment 
modality has been raised. Besides the results and complications, the costs and the time off work and, nowadays-increasingly-even the time off leisure or sport activities and ultimately the quality of life of either treatment modality, must be taken into account.

Prolonged incapacity and handicap from lengthy immobilisation, resulting in serious consequences for employment, intolerance and non-compliance with the cast, was often automatically assumed when advocating primary, minimally invasive screw fixation $[1,2,7,12$, 16]. The surgical approach in contrast was reported to improve the result, reduce the rate of non-union without relevant complications $[1,2,7,12,16]$, and lower the cost; moreover, it allowed early return to work and recreational activities and finally to improve quality of life.

As at our institution undisplaced scaphoid wrist fractures unanimously were treated by cast immobilisation. Data upon the economic impact of the conservative treatment were readily available and without adverse bias. The analysis of these data should clarify the costeffectiveness, the compatibility with early return to work and the resulting potential risks of conservative treatment.

\section{Materials and methods}

The charts of all patients treated at the University Hospital of Bern for undisplaced, isolated scaphoid fracture between 1990 and 2000 were retrospectively reviewed. Patients with additional carpal lesions and patients with isolated fracture of the tubercle (Herbert type A1) were excluded from the study. The diagnosis of a scaphoid fracture was made and routinely confirmed with a series of conventional scaphoid radiographs (postero-anterior projection with the wrist in ulnar deviation, oblique and lateral views) of the wrist. If an isolated undisplaced fracture of the scaphoid was recognised, patients were immobilised in a short arm cast until radiological consolidation was proved. If standard radiographs were inconclusive, additional tri-spiroid tomography (1990-1995) and, beginning in 1996, CT or MRI was obtained.

All patients were followed up clinically and radiologically by a hand surgeon until recovered to full activity, confirmed consolidation of the fracture and complete satisfaction of the patient. The surgeon was free to decide upon the intervals and number of follow-up visits, the need for additional imaging or physiotherapy. The patients were also encouraged to return to work even with the wrist immobilised in the cast. All medical or paramedical acts were recorded on a separate form, allowing the collection of data on direct costs. The Swiss public insurance system, which covers the financial loss caused by the inability to work, permits the individual calculation of indirect costs due to time off work using standard professional codes.

The results were evaluated using Student's $t$-test. Statistical significance was indicated by $p<0.05$.

\section{Results}

Seventy-eight acute isolated undisplaced scaphoid fractures were retrieved. Twenty-four patients $(31 \%)$ were excluded due to incomplete data or insufficient followup. This left 54 patients (47 men, seven women, mean age 30.5, median 27.0, range 16-66 years) for analysis. Twenty-nine patients $(54 \%)$ were manual workers (blue collar) and $15(27 \%)$ were employed in administrative or managerial positions (white collar). Ten patients (19\%) were not formally employed at the time of injury (six students, four housewives). The dominant hand was affected in 28 cases $(52 \%)$.

Eighty-three percent of the fractures (45 patients) were diagnosed within the first $24 \mathrm{~h}$ after the injury. In nine patients $(17 \%)$ the diagnosis and subsequent treatment was delayed by 21 days on average (range 2 30 days). The fractures were localised in the proximal third of the scaphoid in two cases (Herbert type B3) and in the middle third in 52 cases (Herbert type A2 $=19$ cases; Herbert type B1 = seven cases; Herbert type $\mathrm{B} 2=26$ cases). The standard treatment was equal in all cases - applying a cast splint for 3-5 days followed by circular synthetic short arm cast after subsidence of the initial swelling. Fracture healing was monitored and immobilisation discontinued as soon as firm union was assured. Average follow-up lasted 180 ( 63-269) days.

Table 1 shows the duration of immobilisation and the time off work. Average immobilisation lasted 74 (16137) days, 71 days for patients able to work with their cast and 74.4 days for the others. In the group of patients with regular employment $(n=44)$, the total time off work was 74 days on average. Fifteen out of 44 $(34 \%)$ were able to resume their job with the wrist immobilised 17 days after the injury on average. In ten patients without regular employment, the time off work could not be determined. No patient working with the cast had pain complaints or complications related to the early return to work. In the group of patients who did not return to work, four complications were observed: one young patient developed a scaphoid non-union despite prolonged immobilisation and required operative treatment at 8 months. In other three cases $(6 \%)$ the union was delayed necessitating prolonged immobilisation (101,109 and 137 days) until complete radiological consolidation occurred.

At the end of treatment, 39 out of 54 patients $(72 \%)$ were free of symptoms and entirely satisfied despite early return to work. Fifteen patients $(28 \%)$ with mild complaints were given a removable splint for a period of 2 weeks, and only seven patients $(13 \%)$ needed physiotherapy. Fifty-two patients $(96 \%)$ were then able to resume their original work. Two patients with persistent mild pain were re-employed in an equivalent position.

Costs are summarised in Table $2(1$ euro $=1.5$ Swiss francs). The average direct cost was 1,438 Swiss francs per case. This was comprised of costs for material $(37 \%)$, radiographs $(43 \%)$ and medical fees $(20 \%)$. With the occurrence of complications there was a statistically significant increase $(p<0.01)$ in direct costs. Delayed diagnosis and immobilisation had no influence on the healing process and did not affect direct costs $(p=0.62)$. Hand dominance and return to work with the cast did not influence direct costs $(p=0.26 ; p=0.47)$.

The indirect costs of 44 patients covered by workers compensation insurance amounted to 12,639 Swiss 
Table 1 Duration of immobilisation and time off work. N.S. not significant, $N . A$. not applicable

\begin{tabular}{llllll}
\hline & Number & $\begin{array}{l}\text { Average time of } \\
\text { immobilisation (days) }\end{array}$ & $P$ value & $\begin{array}{l}\text { Time off } \\
\text { work (days) }\end{array}$ & $P$ value \\
\hline $\begin{array}{l}\text { Total } \\
\begin{array}{l}\text { Without regular } \\
\text { employment }\end{array}\end{array}$ & 54 & $74(16-137)$ & - & N.A. & - \\
$\begin{array}{l}\text { With regular } \\
\text { employment }\end{array}$ & 44 & 72 & - & N.A. & - \\
$\begin{array}{l}\text { Able to work } \\
\text { despite immobilisation }\end{array}$ & 15 & 71 & N.S. & 74 & - \\
$\begin{array}{l}\text { Unable to work } \\
\text { nnable }\end{array}$ & 29 & 74 & - & 17 & - \\
\hline
\end{tabular}

\begin{tabular}{llll}
\hline & Direct costs & Indirect costs & Total costs \\
\hline Average & 1,438 Sfr $(n=54)$ & 12,639 Sfr $(n=44)$ & $\begin{array}{l}14,077 \text { Sfr }(n=44) \\
\text { Influence of }\end{array}$ \\
Complications & $p<0.01$ & & \\
Delayed diagnosis & N.S. & N.S. & N.S. \\
Hand dominance & N.S. & N.S. & N.S. \\
Able to work & N.S. & N.S. & N.S. \\
\hline
\end{tabular}

Table 2 Costs [1 Swiss franc $(\mathrm{Sfr})=0.73 \$=0.69$ euros $]$. N.S. not significant francs per case on average. No statistical correlation was found between indirect costs and late immobilisation $(p=0.54)$, hand dominance $(p=0.78)$ or complications $(p=0.47)$. In contrast, resuming work despite cast immobilisation substantially reduced indirect costs (by $12,558$ Swiss francs, $p<0.01)$.

The total cost (direct + indirect costs) amounted to 11.779 Swiss francs per case on average, or 14,077 Swiss francs, in patients with regular employment. Thus, the indirect costs represent $90 \%$ of the total cost. No significant correlation was found between total cost and late diagnosis $(p=0.54)$, hand dominance $(p=0.71)$ or complications $(p=0.59)$. And again, resuming work despite cast immobilisation significantly reduced the total costs (by 12.691 Swiss francs, $p<0.01$ ).

No statistical correlation was found between the professional status (white/blue collar) and the time off work $(p=0.31)$, the need for physiotherapy $(p=0.46)$, medical examinations $(p=0.68)$ or imaging $(p=0.70)$.

\section{Discussion}

Conservative treatment of undisplaced scaphoid fractures entails a long immobilisation $[8,9,10,11]$, and the time off work may extend even beyond the immobilisation period $[9,11]$. This treatment $[2,8,9,10,11]$ has traditionally been proposed for cases with no or only minimal displacement [3], since it ensures fracture healing and primary union in $90 \%$ of the cases $[10,11]$ and functional short- and long-term results equivalent or better compared to surgery $[2,12,14]$.

More recently, percutaneous screw fixation has been proposed as an alternative $[1,2,7,12,14,16]$, which may allow early resumption of professional or sports activity $[1,2,12,14]$ while reducing the rates of non-union $[1,2$, $7,14,16]$ and maintaining an excellent quality of life
[2, 12]. With percutaneous screw fixation, conflicting evidence exists regarding duration of incapacity to work. Haddad and Goddard [7] demonstrated reduced time off work, whereas in other studies it was prolonged to more than 8 weeks $[10,12]$, especially in cases of workers' compensation [5].

In order to consider the potential advantages of percutaneous screw fixation with regard to earlier return to work and the resulting cost reduction without prejudice, this needed to be answered for the conservative treatment as well. We have therefore assessed the time off work and the various components of the total costs on a well-defined patient cohort consistently treated with cast immobilisation. The non-union rate $(2 \%)$ compares favourably with the results of operative treatment that shows radiographic union in $92-100 \%$ of patients $[1,2$, $7,12,16]$. Our uniform treatment evidently does not allow for judging the potential of alternative treatment methods for reduction of the direct costs. These direct costs, however, were relatively low, definitely beyond the reach of any surgical therapy. The far more important cost factors $(90 \%)$ were the indirect costs reflecting the time off work.

Immobilisation for a long period, considered by patients and physicians as an obvious obstacle to the resumption of professional activity [6], in our series, was not considered as a factor leading necessarily to a period of time off work. Thus a third of our patients could resume work during the period of immobilisation, and, for the same duration of immobilisation, our times off work were $50 \%$ shorter than in the series of Mink van der Moolen [9] on conservative treatment. Our times off work even approach those observed after mini-invasive treatment $[1,2,7,12,16]$. On the other hand, the group returning to work with the cast experienced no more complications and no less satisfaction with the final result. 
The literature provides no data on how much loading is tolerable, even beneficial, for healing of the various type of undisplaced scaphoid fractures and how much, especially for the eccentrically loaded scaphoid, may even be detrimental. The forces transmitted on and across the scaphoid occur even in a cast, inevitably generated by pure finger motion alone and increased to unknown levels while gripping. Only the residual stability of an impacted fracture and the constraint, displayed by the neighbouring joint surfaces, prevents potential deformation, dislocation and non-union. These decisive determinants are difficult to judge on radiographs, [4, 13] and in retrospect, our distinction based upon the presence/absence of displacement successfully (or just by pure luck) selected the cases with sufficient stability. In our patients, even increased axial loading within reasonable limits had no negative consequences. Interestingly and against the common assumption [15], only a minority of patients $(13 \%)$ needed physiotherapy in order to regain full motion after a considerable length of immobilisation (10 weeks on average), which matches with the literature $[9,10,11]$.

In our series, there was no statistical relationship between the professional status and the duration of immobilisation, the duration of time off work, or the prescription of complementary examinations or of physiotherapy. The social and insurance-related factors thus do not seem to have altered the medical decision, contrary to the observations of Morgan [10] and Filan [5].

The timing of the return to work, however, may be a problematic parameter to interpret and compare, as it is influenced by cultural and insurance-related aspects $[5,10]$, the physician's beliefs in various treatment concepts, the surgeon's experience in assessing fracture consolidation, the patient's health concerns [5] and finally, probably the most important factor, the guidance given. If surgical treatment is advocated, the physician will usually emphasise the possibility of early return to work, and most patients will comply. This approach predetermines obviously the duration of the time off work, as pointed out by Ring [13]. When the same approach of pre-determination is applied to the conservative treatment, as done in this study, it becomes obvious that immobilisation, generally considered as an obvious obstacle to the resumption of professional activity [6], does not necessarily lead to an extended period of time off work.

With this study, we do not pretend to judge the validity of the surgical versus the conservative treatment of the undisplaced fracture of the scaphoid, only to point out some unknown aspects of the latter. The cost analysis has shown that the costs of conservative treatment are predominantly caused by the high indirect costs, resulting from time off work. On the other hand, there is no medical reason that impels nor justifies absence from work during the complete period of immobilisation. With the knowledge that early resumption of merely all activities definitely does not impair successful fracture healing, patients should be encouraged and instructed to return to work as early as possible, as is routinely done after stable percutaneous fracture fixation. This will effectively contribute to massively reduce the indirect cost and therefore also the overall cost of conservative treatment.

The operative, mini-invasive treatment on the other hand cannot be promoted as the only treatment permitting early return to work thereby reducing treatment costs, neither on the base of lower complication rates nor the need for less physiotherapy. It may well lead to a better quality of life during a limited time span, a parameter difficult to assess and document with data that must outweigh the risks of operative treatment. Therefore, prospective comparative and unbiased data are needed.

\section{References}

1. Bond C, Shin AY (2000) Percutaneous cannulated screw fixation of acute scaphoid fractures. Techniques Hand Upper Extremity Surg 4: 81-87

2. Bond CD, Shin AY, McBride MT, Dao KD (2001) Percutaneous screw fixation or cast immobilisation for nondisplaced scaphoid fractures. J Bone Joint Surg [Am] 83: 483-488

3. Cooney WP, Dobyns JH, Linscheid RL (1980) Fracture of the scaphoid: arational approach to management. Clin Orthop 149: 90-97

4. Dias JJ, Taylor M, Thompson J, Brenkel IJ, Gregg PJ (1988) Radiographic sign of union of scaphoid fractures. An analysis of interobserver agreement and reproducibility. J Bone Joint Surg [Br] 70:299-301

5. Filan S (1996) The effect of workers' or third-party compensation on return to work after hand surgery. MJA 165: 80-82

6. Goodwill CJ, Bridges PK, Gardner DC (1969) The causes and costs of absence from work after injury. Ann Physical Medicine 4: $181-186$

7. Haddad FS, Goddard NJ (1998) Acute percutaneous scaphoid fixation. A pilot study. J Bone Joint Surg [Br] 80: 95-99

8. Krasin E, Goldwirth M, Gold A, Goodwin DR (2001) Review of the current methods in the diagnosis and treatment of scaphoid fractures. Postgrad Med J 77: 235-237

9. Mink van der Moolen AB, Groothhoff JW, Visser GJP, Robinson PH, Eisma WH (1999) Time off work due to scaphoid fractures and other carpal injuries in the Netherlands in the period 1990 to 1993. J Hand Surg [Br] 2: 193-198

10. Morgan DAF, Walters JW (1984) A prospective study of 100 consecutive carpal scaphoid fractures Aust N Z J Surg 54: 233 241

11. Raudasoja L, Rawlins M, Kallio P, Vasenius J (1999) Conservative treatment of scaphoid fractures: a follow-up study. Ann Chir Gynecol 88: 289-293

12. Rettig AC, Kollias SC (1996) Internal fixation of acute stable scaphoid fractures in the athlete. Am J Sport Med 24: 182-186

13. Ring D (2002) Nondisplaced scaphoid fractures: assessment and treatment. J Bone Joint Surg [Am] 84: 144-145

14. Saeden B, Törnkvist H, Ponzer S, Höglund M (2001) Fracture of the carpal scaphoid. A prospective randomised 12-year follow-up comparing operative and conservative management. J Bone Joint Surg [Br] 83: 230-234

15. Skirven T, Trope J (1994) Complication of immobilisation. Hand Clin 10: 53-61

16. Yip HS, Wu WC, Chang RYP, So TYC (2002) Percutaneous cannulated screw fixation of acute scaphoid wrist fracture. J Hand Surg [Br] 27: 42-46 